\title{
Modelling of Three-Point Bending Test of Beams With Steel Inclusion Situated in the Middle OF THE SPAN
}

\author{
Michal VYHLIDAL, Zbynek KERSNER \\ Institute of Structural Mechanics, Faculty of Civil Engineering, Brno University of Technology, \\ Veveri 331/95, 60200 Brno, Czech Republic \\ vyhlidal.m@fce.vutbr.cz, kersner.z@fce.vutbr.cz
}

DOI: $10.31490 /$ tces-2018-0020

\begin{abstract}
The aim of this paper is to present the numerical model of the fracture response of the test specimens with a steel inclusion in the shape of the prisms which length is equal to the specimen's width. Specially designed fine-grained cement-based matrix specimens of the nominal dimension $40 \times 40 \times 160 \mathrm{~mm}$ with inclusion of $8 \times 8 \times 40 \mathrm{~mm}$ and central edge notch serves to determine of the influence of the interfacial transition zone on the effective mechanical fracture parameters of composite. The numerical models of three-point bending test of these specimens are created in ATENA software.
\end{abstract}

\section{Keywords}

Fine-grained composite, Interfacial Transition Zone, numerical model, steel inclusion, threepoint bending.

\section{Introduction}

Silicate-based materials, in this case fine-grained cement based composite, belong to the widely used building materials. These composites show nonlinear, more precisely, quasi-brittle behaviour - the ability to carry load continues even after the deviation from the linear branch of load-displacement diagram until the peak point and then the decrease of loading force follows until the failure, so called tensile softening 11. The reason for this behaviour would be, except of strong heterogeneity, the existence of the interfacial transition zone.

In order to determine the response of construction/structural elements from quasi-brittle materials, knowledge of a number of material parameters is nec- essary. These parameters are often determined based on the results of destructive tests. One of the most used destructive method for testing specimens from quasibrittle materials is the three-point bending test configuration [2]. In the case of fracture tests, the test specimens are also provided by initial central edge notch.

\section{Interfacial Transition Zone}

The interfacial transition zone (ITZ), originally "aureole de transition", is a region close to the aggregate grain / inclusion / reinforcement which has been the subject of studies since the 1950s [3]. This region of about $50 \mu \mathrm{m}$ in size is due to the so-called "wall effect" and other well or less-known processes and its significant feature is mainly higher porosity 4 . The ITZ microstructure consists mainly of calcium hydroxide crystals and ettringite. On the contrary, ITZ shows a reduced amount of unhydrated cement grains [5].

Due to the local increase in porosity, the lower values of the mechanical fracture parameters of ITZ are also expected. These expectations were confirmed by nanoindentation tests performed on specimens with rock inclusions [6].

It is clear that the ITZ can be considered as the weakest element of cement composites and could have significant impact on the fracture behaviour of such composites.

\section{Experimental part}

The special specimens were designed to determine the effect of the ITZ on the overall behaviour of cement composite. Test specimens with dimensions of $40 \times$ 

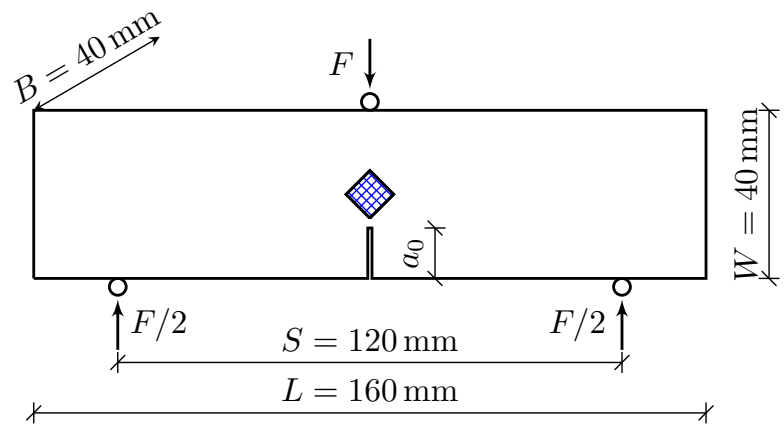

Fig. 1: Specimen geometry and three-point bending fracture test configuration.

$40 \times 160 \mathrm{~mm}$ contain internal steel inclusion with dimensions of $8 \times 8 \times 40 \mathrm{~mm}$ which was placed in the middle of the span above the initial notch (in the middle of specimen depth), see Fig. 1. The notch depth was $a_{0}=12 \mathrm{~mm}$.

\subsection{Materials and specimens}

For the purpose of this study, two sets of test specimens were made, first set contained 3 specimens with steel inclusion and the second one contained 3 reference specimens (without inclusion) which were used to determine the mechanical fracture parameters of the matrix. Composition of the composite was designed by Dr. Barbara Kucharczyková from the Institute of Building Testing at the Faculty of Civil Engineering, Brno University of Technology (FCE BUT).

Due to the dimensions of the test specimens (Fig. 1), a fine-grained cement based composite was chosen. The fresh mixture was made using the standardized quartzite sand with maximum nominal grain size of $2 \mathrm{~mm}$, Portland cement CEM I 42.5 R (cement plant Mokrá) and water at a ratio of 3:1:0.35. To increase the workability of the fresh mixture, the polycarboxylate ether-based superplasticizer SIKA SVC 4035 was used at an amount of $1 \%$ by cement mass. Bulk density of such a composite was $2280 \mathrm{~kg} / \mathrm{m}^{3}$.

To increase adhesion, steel inclusions surfaces have been roughened, see the scanning electron microscopy (SEM) micrograph cause by detection of secondary electrons (SE) with accelerating voltage of electrons $20 \mathrm{kV}$ (Fig. 2). The micrograph was taken by Dr. Patrik Bayer from the Institute of Chemistry FCE BUT.

The components were mixed in a laboratory conditions using the hand-held paddle mixer at the Institute of Chemistry FCE BUT under the supervision of associate professor Pavel Rovnaník. Three-part polypropylene moulds were used to produce the test specimens. Before their filling, the steel inclusions were fixed

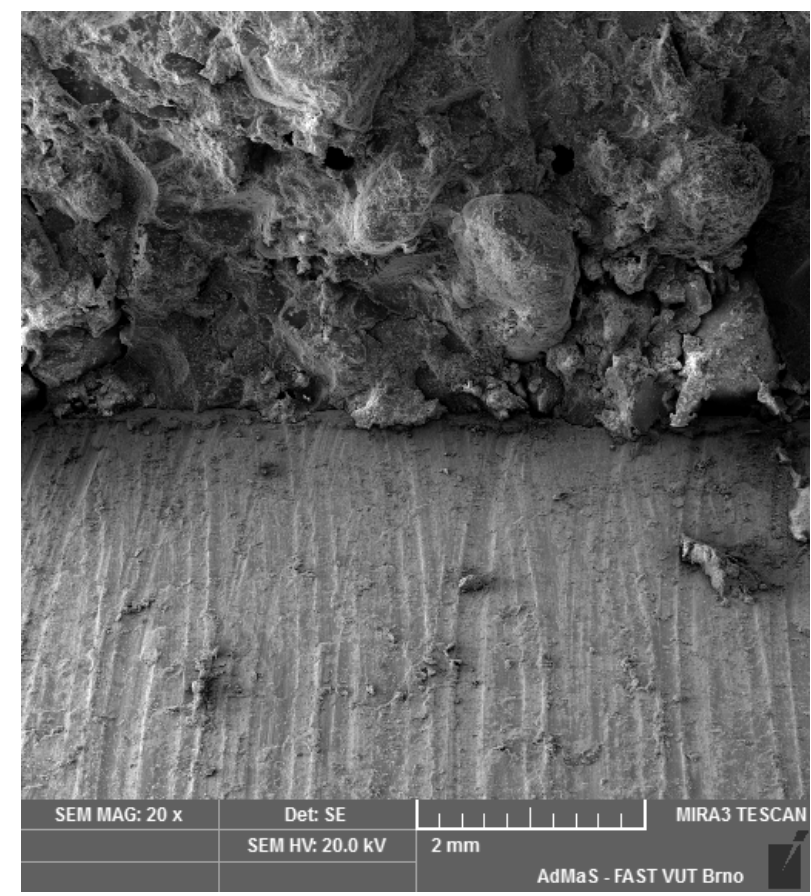

Fig. 2: Microstructure of steel-matrix interface by detection of SE with magnification $20 \times$.

in the position in each part of the form. After pouring and compaction of the fresh mixture, the moulds was sealed with a thin PE foil and placed in the stabilized laboratory conditions for 3 days. After demoulding, the test specimens had been stored in water bath until their testing. After 14 days, the specimens were removed from water bath, provided by initial central edge notch with depth $a_{0}=12 \mathrm{~mm}$ and tested in the configuration of the three-point bending fracture test in the AdMaS research center FCE BUT by Dr. Barbara Kucharczyková and Dr. Petr Daněk.

\subsection{Results of fracture tests}

The fracture tests were carried out using LabTest 61000.1.10 testing machine with displacement control. During the tests, force versus displacement, i.e. deflection in the midspan, $(F-d)$ diagrams and force versus crack mouth opening displacement $(F-C M O D)$ diagrams were recorded. However, only a development of the force $F$ in $(\mathrm{kN})$ depending on the value of deflection $d$ in $(\mathrm{mm})$ are presented in this paper.

Figure 3(a) shows such a development of the force $F$ depending on the value of deflection $d$ typical for specimens without inclusion, while the typical crack propagation shows Fig. [3(b) It is clear from the diagrams that the maximum force value $F_{\max } \approx 1.05 \mathrm{kN}$.

The $F-d$ diagrams were used for the determination of elasticity modulus $E$ in $(\mathrm{GPa})$ and specific fracture energy $G_{\mathrm{F}}$ in $(\mathrm{N} / \mathrm{m})$. According to [1, the first almost 


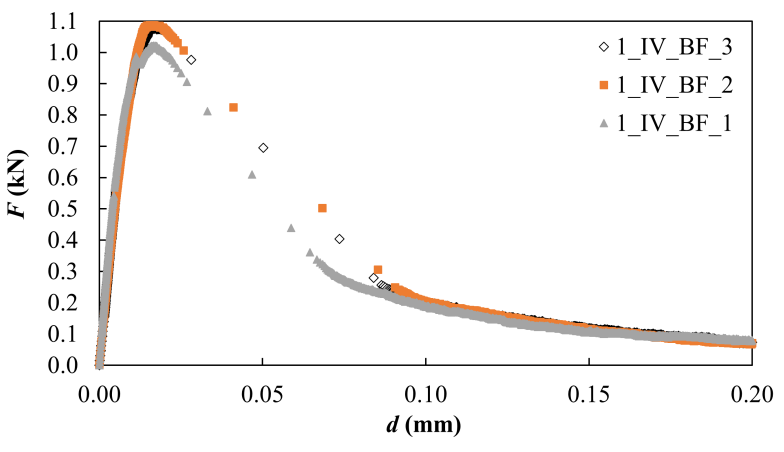

(a) Typical $F-d$ diagrams.

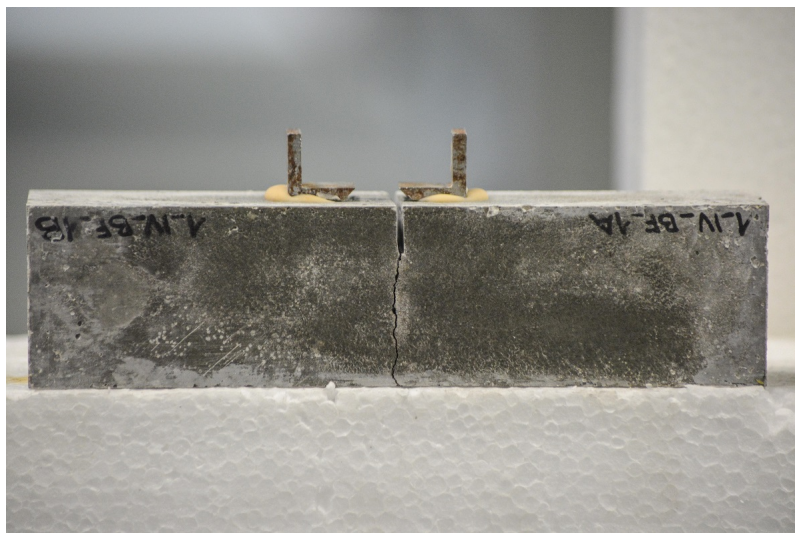

(b) Typical crack propagation.

Fig. 3: Results of the fracture test of specimens without inclusion in different graphic displays (a) Typical development of the variable $F(\mathrm{kN})$ depending on the value of $d(\mathrm{~mm}),(\mathrm{b})$ Typical crack propagation.

linear part of measured $F-d$ diagrams, which reaches up half of $F_{\max }$, was used to estimate the $E$ values, while $G_{\mathrm{F}}$ was determined using work of fracture $W_{\mathrm{F}}$ method according to the following relation [2]:

$$
G_{\mathrm{F}}=\frac{W_{\mathrm{F}}}{A_{\mathrm{lig}}}
$$

where $W_{\mathrm{F}}$ is work of fracture in $(\mathrm{N} \cdot \mathrm{m})$ and $A_{\text {lig }}$ is ligament area in $\left(\mathrm{m}^{2}\right)$. It is clear from the Eq. 1 that $G_{\mathrm{F}}$ is the energy required to create a unit size fracture area. In comparison with $G_{\mathrm{F}}$, work of fracture $W_{\mathrm{F}}$ in $(\mathrm{N} \cdot \mathrm{m})$ expresses the work of force $F$ in $(\mathrm{kN})$ at the deflection $d$ in $(\mathrm{mm})$ and is defined as an area under $F-d$ diagram. By using integral calculus we obtain the following Eq. 2 ,

$$
W_{\mathrm{F}}=\int_{0}^{d} F \mathrm{~d} d
$$

where $F$ is applied force in $(\mathrm{kN})$ and $\mathrm{d} d$ is differential increment of deflection in $(\mathrm{mm})$.

Selected mechanical fracture parameters values of matrix estimate by using academic software called StiCrack [7] are introduced in Tab. 1. Ligament area was estimated for straight vertical crack propagation direction, so the value is $A_{\text {lig }}=1.12 \cdot 10^{-3} \mathrm{~m}^{2}$. This value is for sure underestimated, because the real crack's area is in fact fractal object and it is very difficult to find it out.

On the other hand, specimens with steel inclusion show a significant decrease in the maximum force value $F_{\max }$ as well as decrease in the specific fracture energy values $G_{\mathrm{F}}$. The reason may be due to the existence of the ITZ, as will be discussed below. Selected mechanical fracture parameters values of specimens with steel inclusion estimate by using StiCrack
Tab. 1: Selected mechanical fracture parameters values of matrix; basic statistics - mean values, standard deviations, coefficients of variation.

\begin{tabular}{ccccc} 
Label & $F_{\max }(\mathrm{kN})$ & $W_{\mathrm{F}}(\mathrm{N} \cdot \mathrm{m})$ & $G_{\mathrm{F}}(\mathrm{N} / \mathrm{m})$ & $E(\mathrm{GPa})$ \\
\hline $\mathrm{BF}-1$ & 1.02 & 0.070 & 62.79 & 47.4 \\
$\mathrm{BF}^{-2}$ & 1.09 & 0.082 & 72.84 & 40.7 \\
$\mathrm{BF}$ 3 & 1.08 & 0.078 & 69.52 & 42.7 \\
\hline Mean v. & 1.06 & 0.077 & 68.40 & 43.6 \\
St. Dev. & 0.04 & 0.006 & 5.12 & 3.4 \\
CoV $(\%)$ & 3.6 & 7.5 & 7.5 & 7.9
\end{tabular}

software [7] are introduced in Tab. 22 Ligament area of specimens with steel inclusion was estimated as $A_{\text {lig }}=1.30 \cdot 10^{-3} \mathrm{~m}^{2}$ which agree with the crack propagation direction in Fig. 4(b).

Tab. 2: Selected mechanical fracture parameters values of specimens with steel inclusion; basic statistics - mean values, standard deviations, coefficients of variation

\begin{tabular}{cccc} 
Label & $F_{\max }(\mathrm{kN})$ & $W_{\mathrm{F}}(\mathrm{N} \cdot \mathrm{m})$ & $G_{\mathrm{F}}(\mathrm{N} / \mathrm{m})$ \\
\hline STE_1 & 0.39 & 0.038 & 29.31 \\
STE_2 & 0.40 & 0.049 & 37.19 \\
STE_3 & 0.36 & 0.037 & 28.61 \\
\hline Mean value & 0.38 & 0.041 & 31.7 \\
St. Dev. & 0.02 & 0.006 & 4.76 \\
CoV $(\%)$ & 5.4 & 15.0 & 15.0
\end{tabular}

$F-d$ diagrams of specimens with steel inclusion are different from the matrix one, see Fig. 4(a). The ascending branches of the second and the third specimen consist of two almost linear parts. The reason could be in the change of crack propagation direction in comparison with the matrix specimens, see Fig. 4(b). $F-$ $d$ diagram of the first specimen with steel inclusion is different from the others. The reason could be the existence of the hollow near the inclusion tip.

Obviously, parameters introduced in the tables above are calculated from a small number of samples and therefore these are not representative, especially in the case of specimens with steel inclusion. Unfortu- 


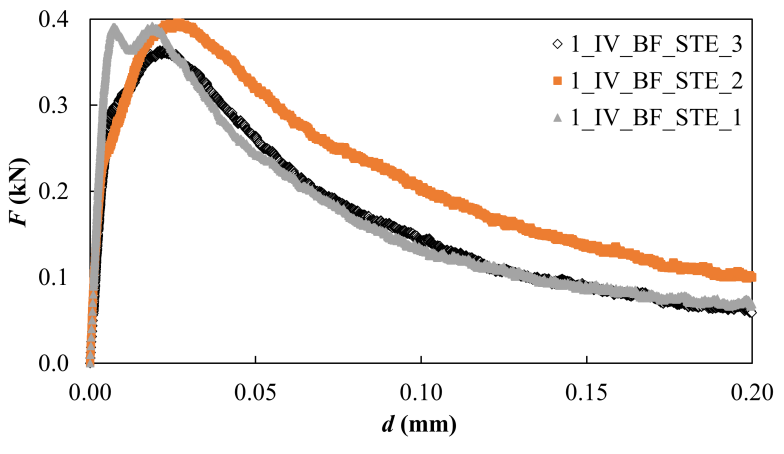

(a) Typical $F-d$ diagrams.

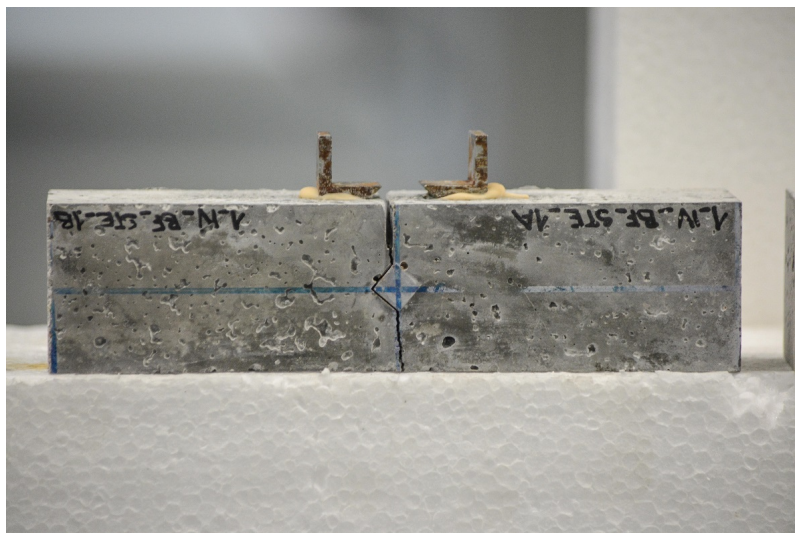

(b) Typical crack propagation.

Fig. 4: Results of the fracture test of specimens with steel inclusion in different graphic displays (a) Typical development of the variable $F(\mathrm{kN})$ depending on the value of $d(\mathrm{~mm}),(\mathrm{b})$ Typical crack propagation.

nately, other relevant data / tests have not been available yet, so these data have to be sufficient for this study.

\section{Numerical study}

In order to verify the hypothesis about the influence of ITZ on the overall behaviour of the cement composite, numerical model of the test specimen was created in the ATENA software [8]. The finite element (FE) analysis software ATENA is used for nonlinear analysis of structures and includes tools designed to simulate quasi-brittle fracture.

A simplified 2D model of plane strain with a thickness of $40 \mathrm{~mm}$ was chosen due to specimen thickness. If we considered a 2D model of plane stress, the thickness of the specimen would have to be in units of centimetres. Another reason for choosing plane strain is as follows. If we keep the following recommendations [1, 9]:

- the least dimension of specimen should be greater than $5 g$, where $g$ is the maximum grain size of the aggregate,

- specimen's width should be in the range of $40-$ $-100 \mathrm{~mm}$,

- specimen's length should be 4 times greater than specimen's width,

- ratio $\alpha=a_{0} / W$ should be in the range of $0.2-$ -0.6 ,

mechanical fracture parameters will be independent of the dimensions, primarily of the thickness, of the specimen. It has been known for a long time that mechanical fracture parameters values are approaching a certain constant, usually minimum, value in the case of plane strain loading conditions [10, 11].

In order to verify the hypotesis, 3 models were created and the difference between these models was only in the materials used for the individual layers. The model scheme including the finite element mesh was the same for all three variants, see Fig. 5 .

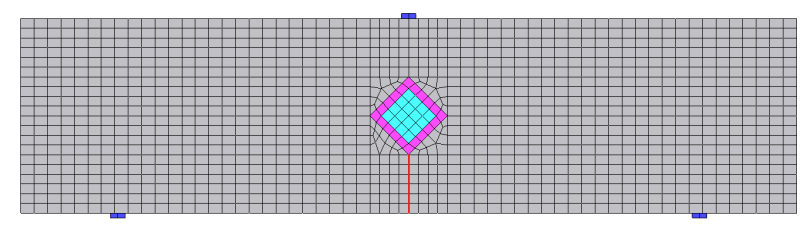

Fig. 5: Scheme of numerical model of three-point bending fracture test with a crack length of $a_{0}=12 \mathrm{~mm}$ in ATENA software, including color identification of layers - matrix, inclusion and ITZ.

Due to the unknown values of the ITZ parameters and the other simplifications, a relatively large finite element size around the inclusion was chosen. The numerical model only served to confirmation of the hypothesis of imperfect adhesion between ITZ and aggregate and of the influence of the ITZ on the overall behaviour and did not serve to inverse determination of the ITZ properties. For these purposes, the finite elements size appears to be sufficient.

Material models were used as follows. Material model of the matrix and the ITZ were CC3DNonLinCementitious2 which is based on the orthotropic smeared crack theory in combination with the crack band model complemented by Rankine failure criterion and exponential softening [8]. A bilinear material model complemented by Mises failure criterion was used to simulate the behaviour of inclusion and an elastic material was used for the steel plates. 
Selected material parameters used in numerical model can be found in Tab. 3. Values of ITZ's parameters were estimate as $50 \%$ of values of the matrix (MTX) parameters according to the homogenization technique called generalized self-consistent scheme (GSCS) [12]. This technique can be applied to the area of a few micrometers in width, however it can be considered as sufficient for this study.

Tab. 3: Selected material parameters used in FE model.

\begin{tabular}{ccccc} 
Mat. & $E(\mathrm{GPa})$ & $f_{\mathrm{t}}(\mathrm{MPa})$ & $f_{\mathrm{c}}(\mathrm{MPa})$ & $G_{\mathrm{F}}(\mathrm{N} / \mathrm{m})$ \\
\hline MTX & 43.6 & 3.0 & -49.6 & 68.4 \\
ITZ & 21.8 & 1.5 & -24.8 & 34.2
\end{tabular}

The displacement increment loading was applied to the top plate and loading speed was similar to the real tests, i.e. $0.03 \mathrm{~mm}$ per minute (step).

\section{1. $\quad$ Model 1}

The first model contained only the matrix and served to verification of the measured mechanical fracture parameters. The calculated $F-d$ diagram can be found in Fig. 6. As you can see, the ascending branch is almost identical to the measured ones, while the descending branch is different.

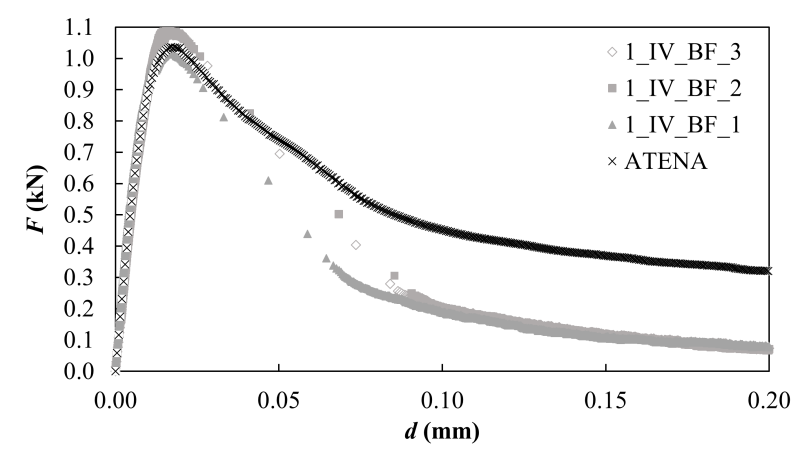

Fig. 6: Calculated $F-d$ diagram of specimen without inclusion with the measurement at background.

One of the reasons why the descending branch is different may be a disruption of the quasi-static loading condition after the peak point during real fracture tests.

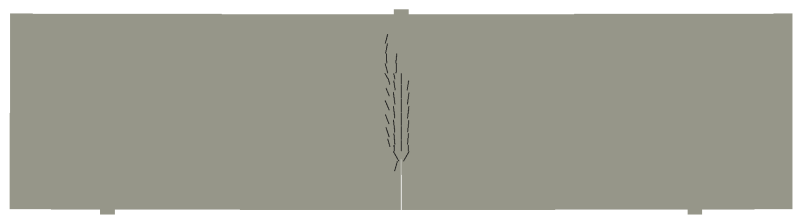

Fig. 7: Calculated crack propagation direction for specimen without inclusion.

Crack propagation directions can be seen in Fig. 7 The crack width $0.05 \mathrm{~mm}$ was chosen which is the minimum value of the crack width that can be visually identified. Crack propagation direction corresponds to the observed one.

\section{2. $\quad$ Model 2}

The second model contained matrix and steel inclusion (without ITZ). The calculated $F-d$ diagram can be found in Fig. 8. The maximum force value when considering perfect adhesion and without the ITZ has higher values than the matrix itself.

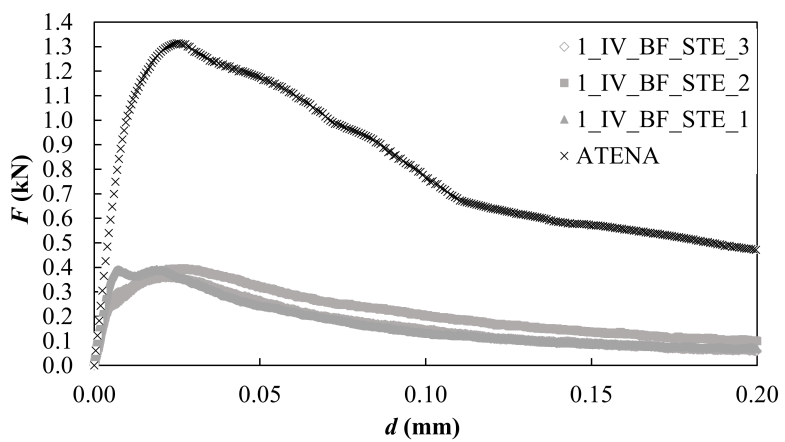

Fig. 8: Calculated $F-d$ diagram of specimen with inclusion with the measurement at background.

Crack propagation directions of the specimen with inclusion can be seen in Fig. 9. The crack width was $0.05 \mathrm{~mm}$ again. Crack propagation direction does not correspond to the observed one. The reason may be due to the existence of the ITZ, imperfect adhesion or their combination.

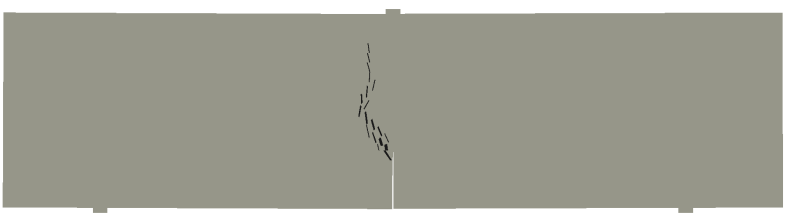

Fig. 9: Calculated crack propagation direction for specimen with inclusion.

\section{3. $\quad$ Model 3}

The third model contained in addition to two materials mentioned above the ITZ layer, but at a thickness of $2 \mathrm{~mm}$. Although this thickness disagree with the average thickness of $50 \mu \mathrm{m}$, as it is often estimated in the literature, it was necessary to use it. The reasons come from the heart of the matter of the used material models for matrix and ITZ which is not very suitable for analysis of such a small area. The reason comes from used crack opening law. In this case, exponential crack opening law was used, where the crack opening at the complete release of stress $w_{\mathrm{c}}$ is defined:

$$
w_{\mathrm{c}}=5.14 \cdot \frac{G_{\mathrm{F}}}{f_{\mathrm{t}}^{e f}},
$$


where $G_{\mathrm{F}}$ is fracture energy and $f_{\mathrm{t}}^{e f}$ is the effective tensile strength.

If we consider $f_{\mathrm{t}}^{e f}=f_{\mathrm{t}}=3.0 \mathrm{MPa}$ for simplification, where $f_{\mathrm{t}}$ is the uniaxial tensile strength, we will get:

$$
w_{\mathrm{c}}=5.14 \cdot \frac{68.4}{3 \cdot 10^{6}}=1.17 \cdot 10^{-4} \mathrm{~m}=117 \mu \mathrm{m}
$$

The use of elements, which are smaller than the crack opening at the complete release of stress $w_{\mathrm{c}}$, does not make any physical meaning. From that reason, we decided to use the element's size equal to the value of maximum nominal aggregate grain size, which has a clear physical meaning.

To control localization of deformations in the failure state, a localization limiter is implemented in ATENA, which meets the requirement that the results must be independent of mesh choice. This approach is known as the crack band theory [8, 13]. The main idea of crack band model is to provide a constant energy dissipation per unit of the damaged area in each element. The failure bands are defined as projections of the finite element dimensions on the failure planes, which direction is assumed to be normal to principal stresses.

Another reason, why these procedures are not suitable for analysis of very small areas, is that the calculation collapses in the case of a combination of very small elements with the large ones. Due to the large computational demands, no model, which consisted only from a small elements, was created.

Despite this imperfection, a decrease in the maximum load value compared to the model 1 (only matrix) can be seen in Fig. 10. The reason for the decrease is the existence of zone of "weakness" in which the crack will propagate. The ascending branch in Fig. 10 also consists of two almost linear parts as well as in the case of experimental specimens number two and three. However, angle between these branches is approximately $90^{\circ}$, on the contrary the value of the angle is much higher in the case of experimental results. It is probably due to the imperfect adhesion.

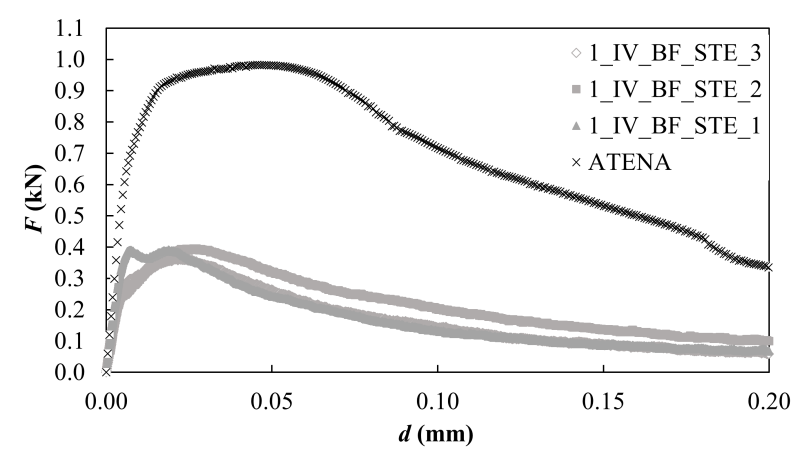

Fig. 10: Calculated $F-d$ diagram of specimen with ITZ and inclusion with the measurement at background.
Crack propagation directions of the specimen with inclusion and the ITZ can be seen in Fig. 11 The crack width was $0.05 \mathrm{~mm}$ again. We also see that the crack propagation direction does not corresponds to the observed one. The reason is probably the imperfect adhesion between ITZ and steel inclusion. As a result, the crack propagates directly through the ITZ-inclusion interface towards the upper surface of the specimen.

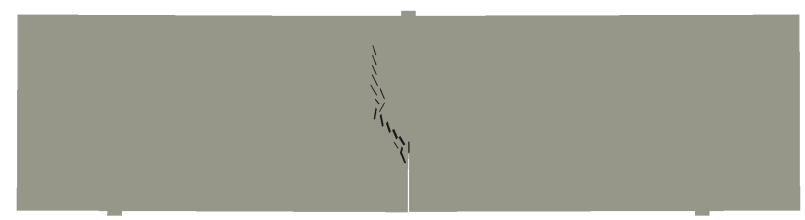

Fig. 11: Calculated crack propagation direction for specimen with ITZ and inclusion.

\section{Conclusion}

From the detailed numerical analysis of the described fracture test is obvious that the maximum load was reduced due to the presence of the ITZ around steel inclusion. Moreover, there is a change in crack propagation direction in the case of model 3 (containing the ITZ and considering perfect adhesion) compared to real/observed propagation. This change in crack propagation direction implies that the problem with the existence of zone of "weakness" (ITZ) with lower values of mechanical fracture parameters is much more complicated due to the imperfect adhesion.

It is clear that the ITZ can be considered as the "weakest element" of cement composites. In view of this fact it is necessary to accept the existence of the ITZ as a fundamental fact and to deal with the ways of its modification.

\section{Acknowledgment}

This outcome has been achieved with the financial support of the Czech Science Foundation under project No. 16-18702S AMIRI and with the financial support of the Brno University of Technology (project of junior specific university research FAST-J-18-5355).

\section{References}

[1] KARIHALOO, B.L. Fracture Mechanics and Structural Concrete. New York: Longman Scientific \& Technical, 1995. ISBN 0-582-21582-X. 
[2] RILEM Technical Committee 50-FMC. Determination of the fracture energy of mortar and concrete by means of three-point bend test on notched beams. Materials and Structures. 1985, vol. 18, iss. 4, pp. 287-290. ISSN 1871-6873. DOI: 10.1007/BF02472918.

[3] FARRAN, J. Contribution mineralogique a l'etude de l'adherence entre les constituants hydrates des ciments et les materiaux enrobes. Revue des Matiriaux de Construction . 1956, vol. 490, pp. $155-172$.

[4] SCRIVENER, K.L., A.K. CRUMBIE, P. LAUGESEN. The Interfacial Transition Zone (ITZ) Between Cement Paste and Aggregate in Concrete. Interface Science. 2004, vol. 12, iss. 4, pp. 411-421. ISSN 1573-2746. DOI: 10.1023/B:INTS.0000042339.92990.4c

[5] DIAMOND, S. and J. HUANG. Interfacial Transition Zone: Reality or Myth? In: Katz, A. et al. (Ed.) RILEM Second International Conference on the Interfacial Transition Zone in Cementitious Composites. London: E \& FN Spon, 1998, pp. 3-39. ISBN 0-419-24310-0.

[6] ZACHARDA, V., J. NEMECEK, H. SIMONOVA, B. KUCHARCZYKOVA, M. VYHLIDAL and Z. KERSNER. An Influence of Interfacial Transition Zone on Local and Overall Fracture Response of Cementitious Composites. In: Book of abstracts 13th Conference on Local Mechanical Properties. Košice: Institute of Materials Research of SAS, 2017, pp. 26-27.

[7] STIBOR, M. Fracture Parameters of QuasiBrittle Materials and Their Determination. Brno, 2004. Doctoral thesis. Brno University of Technology. Supervisor: Zbyněk Keršner.

[8] CERVENKA, V., L. JENDELE and J. CERVENKA. ATENA Program documentation - Part 1: Theory. Praha: Červenka Consulting, 2016

[9] NALLATHAMBI, P. and B.L. KARIHALOO. Determination of specimen-size independent fracture toughness of plain concrete. Magazine of Concrete Research. 1986, vol. 38, iss. 135, pp. 67-76. ISSN 1573-2746. DOI: $10.1680 /$ macr.1986.38.135.67.

[10] LAI, M.O. and W.G. FERGUSON. Effect of Specimen Thickness on Fracture Toughness. Engineering Fracture Mechanics. 1986, vol. 23, iss. 4, pp. 649-659

[11] NEVALAINEN, M. and K. WALLIN. The Effect of Crack Depth and Absolute Thickness on Fracture Toughness of 3PB Specimens. In: Schwalbe,
K.-H. and C. Berger (Ed.) ECF10 - Structural Integrity: Experiments-Models-Applications. Berlin: EMAS Publishing, 1994, pp. 997-1006.

[12] HASHIN, Z. and P. MONTEIRO. An inverse method to determine the elastic properties of the interphase between the aggregate and the cement paste. Cement and Concrete Research. 2015, 2002, vol. 32, Iss. 8, pp. 1291-1300. ISSN 0008-8846. DOI: 10.1016/S0008-8846(02)00792-5

[13] BAZANT, Z. and B.H. OH. Crack band theory for fracture of concrete. Matériaux et Construction. 1983, vol. 16, iss. 3, pp. 155-177. ISSN 18716873. DOI: $10.1007 / \mathrm{BF} 02486267$.

\section{About Authors}

Michal VYHLIDAL was born in Kojetin (district Prerov), Czech Republic. He received his M.Sc. from Construction and Traffic Structures at the Faculty of Civil Engineering, Brno University of Technology, Czech Republic in 2018. His research interests include Interface Fracture Mechanics and the Interfacial Transition Zone in cement based composites.

Zbynek KERSNER was born in Boskovice (district Blansko), Czech Republic. He is Professor at Institute of Structural Mechanics, Brno University of Technology, Czech Republic. His expertise and research activities: Fracture mechanics of quasi-brittle materials (cement based composites, alkali activated concretes, rocks), mechanical fracture parameters, fracture process zone, interfacial transition zone, and reliability analyses of structures. 